LA-UR- $95-2815$

Title:

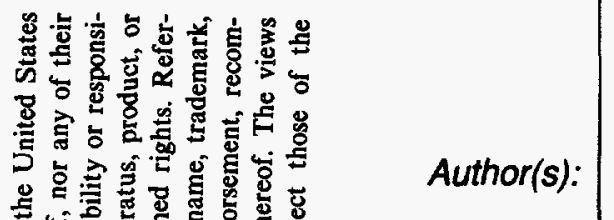

Submitted to:

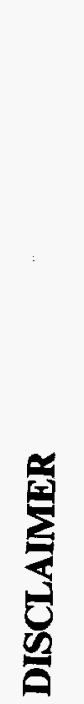

\section{Los Alamos}

NATIONAL LABORATORY
CAPACITOR AND RAIL-GAP DEVELOPMENT FOR THE ATLAS MACHINE MARX MODULES

W. A. REASS, P-24

D. W. BOWMAN, DX-17

R. F. GRIBBLE, P-22

J. R. GRIEGO, DX-17

C. THOMPSON, P-22

W. M. PARSONS, P-22

R. A. COOPER, MAXWELL LABORATORIES

D. C. CASPER, MAXWELL LABORATORIES

10th IEEE International Pulsed Power Conference July $10-13,1995$ 


\section{DISCLAIMER}

Portions of this document may be illegible in electronic image products. Images are produced from the best available original document. 


\title{
CAPACITOR AND RAIL-GAP DEVELOPMENT FOR THE ATLAS MACHINE MARX MODULES
}

\author{
b y \\ W.A. Reass, D.W. Bowman, R.F. Gribble, J.R. Griego, C. Thompson, \\ and W.M. Parsons \\ Los Alamos National Laboratory \\ P. O. Box 1663, Los Alamos, NM 87545 \\ and \\ R.A. Cooper and D.C. Casper \\ Maxwell Laboratories \\ 9244 Balboa Ave., San Diego, Ca. 92123
}

\begin{abstract}
This paper presents the engineering issues and development criteria utilized to evolve the Atlas Marx bank pulse power components. The capacitor and rail-gap required alterations from existing designs to minimize system inductance and component count, maximize reliability, and enhance maintainability. For the capacitors, development has resulted in a plastic cased device with double ended bushings. The design of the capacitors' output electrodes, foil packs, and internal interconnect webbing results in a capacitor with improved performance. The capacitors are rated at $33.5 \mathrm{uF}$ and $60 \mathrm{kV}$ and are housed in a $28^{\prime \prime} \times 29^{\prime \prime} \times 13^{\prime \prime}$ fiberglass case. Terminal inductance is less than $15 \mathrm{nH}$ with a design discharge current greater than $650 \mathrm{kA}$.

An improved "third generation" railgap will be utilized and is a product of the ACE machine developments at Maxwell Laboratories. The gap has a polyurethane body and one piece electrodes. To minimize prefires, a modified internal profile reduces the E-field and increases tracking length between the electrodes. With an individual Marx stage charged "+" and "-" and a trigger rail with 50/50 grading (mid-plane), external trigger bias or coupling components are not required. This further reduces system component count. To further reduce gap prefires and environmental concerns, high pressure air, instead of the typical Argon/SF6 mixture, will be used. The metallic switching by-products will form insulating oxides and the gap flushing procedures are simplified. To ensure multi-channel discharges, fast $\mathrm{dV} / \mathrm{dT}$ trigger voltages $(\sim 30 \mathrm{kV} / \mathrm{nS})$, similar to those developed for the Staged Theta-Pinch railgaps (a Scyllac era machine at Los Alamos), will be utilized.
\end{abstract}

\section{CAPACITORS}

Most low inductance pulsed power machines still use older metal case capacitor technology. To properly insulate for high voltage between metal cases, bushings, and other assemblies, dielectric oil, mylar, paper, and/or special gaskets and hats are typically used. In addition, to interface between capacitors, switches, and transmission lines, many other machined components are also required. For large machines, the cost of manufacture, assembly, and other reliability issues may become a major concern. One method that minimizes component count and system inductance, is to stack plastic cased capacitors, with electrodes on each end, on top of one another. One could then connect switches on one set of terminals and output transmission plate lines on the opposite electrodes. This design is the basis of the Atlas machine design, and is detailed in the proceedings of this meeting. The Ace II and Ace IV machines developed at Maxwell Laboratory, uses a similar design (1). In 
these machines, two capacitors were built into one plastic case with four bushings, two on each side. This style of capacitor is called FASTCAP. A switch is connected between electrodes on one side and the output taken on the other pair of electrodes on the opposite side. By placing two series (Marxed) capacitors in one case, the flux region between the capacitors can be minimized, only the thickness of the insulating kraft paper stack between the two foil sets. The design trade-off is the requirement of insulating oil to ensure reliable hold-off between the charged capacitor electrodes (under the switch). Atlas will use a single element fiberglass cased capacitor, with large flat bushings on each end, as shown in Figure 1. The charging voltage stress is along the length of the capacitor, providing the possibility of reliable system operation in air. The design trade-off is the increased space between capacitors, which sacrifices some machine inductance. The calculated inductance for this leakage flux area is about $15 \mathrm{nH}$ per Marx stage. The Atlas capacitor is being developed with the performance characteristics as given in Table 1.

\title{
TABLE 1: ATLAS CAPACITOR RATINGS
}

\author{
$60 \mathrm{kV}, 33.5 \mathrm{uF}, 60 \mathrm{~kJ}, 15 \mathrm{nH}$ \\ Normal Discharge Current: $420 \mathrm{kA}$ \\ Fault Discharge Current: $720 \mathrm{kA}$ \\ Reversal: $20 \%$ \\ Lifetime: 2,400 shots @ 95\% Survival With 20\% Reversal \\ Double Ended Fastcap with 2" x 20" Bushings \\ .125 Thick Fiberglass Case \\ $13 " \mathrm{H}$ x 29" W x 28" D Case ( 6 J/Cu In)
}

The anticipated design for the capacitor dielectric system is conventional paper, foil, and castor oil. This technology has a large data base and is capable of the large pulse currents we require. Los Alamos will also be examining self clearing metalized foil and plastic dielectric capacitor designs. This technology can offer the capability of increased energy density, reduced size, and reduced weight. There is a not an existing data base at the 500 to 750 kiloAmp levels that Atlas requires, however a few devices have been fault mode tested for a few shots in the $200 \mathrm{kA}$ regime for electrothermal guns. It should, therefore, be possible to scale self clearing designs, to the Atlas requirements. To minimize capacitor inductance, the full width of the paper stock will be utilized, with floating foils for series sections. This provides the best area utilization and avoids soldering smaller, series connected foil packs. The actual method of foil pack construction and capacitor internal bushing interconnects also affect inductance. Wide interconnect webs are used to attach between the foil packs and output bushings. A major concern is to ensure a reliable oil seal on the final fiberglass case assembly. Methods are being examined with various combinations of o-ring and epoxy seals.

\section{RAILGAPS}

The Atlas bank design uses resistive damping to minimize capacitor reversal and transmission line ringing. The near critical damping also has the added benefit of reducing and limiting coulomb transfer through the railgaps during a bank or transmission line failure. Railgap performance requirements are shown in Table 2 . 


\section{TABLE 2: RAILGAP PERFORMANCE REOUIREMENTS}

$\begin{array}{ll}\text { NOMINAL CURRENT } & 420 \mathrm{KA} \\ \text { FAULT CURRENT } & 720 \mathrm{KA} \\ \text { COULOMB TRANSFER } & 2.0 \mathrm{C} \\ \text { FAULT COULOMBS } & 2.4 \mathrm{C} \\ \text { VOLTAGE } & 120 \mathrm{KV} \\ \text { PREFIRE RATE } & 1 \mathrm{IN} 10000 \\ \text { PRESSURE RATING } & 120 \text { PSI } \\ \text { INSULATING GAS } & \text { DRY AIR }\end{array}$

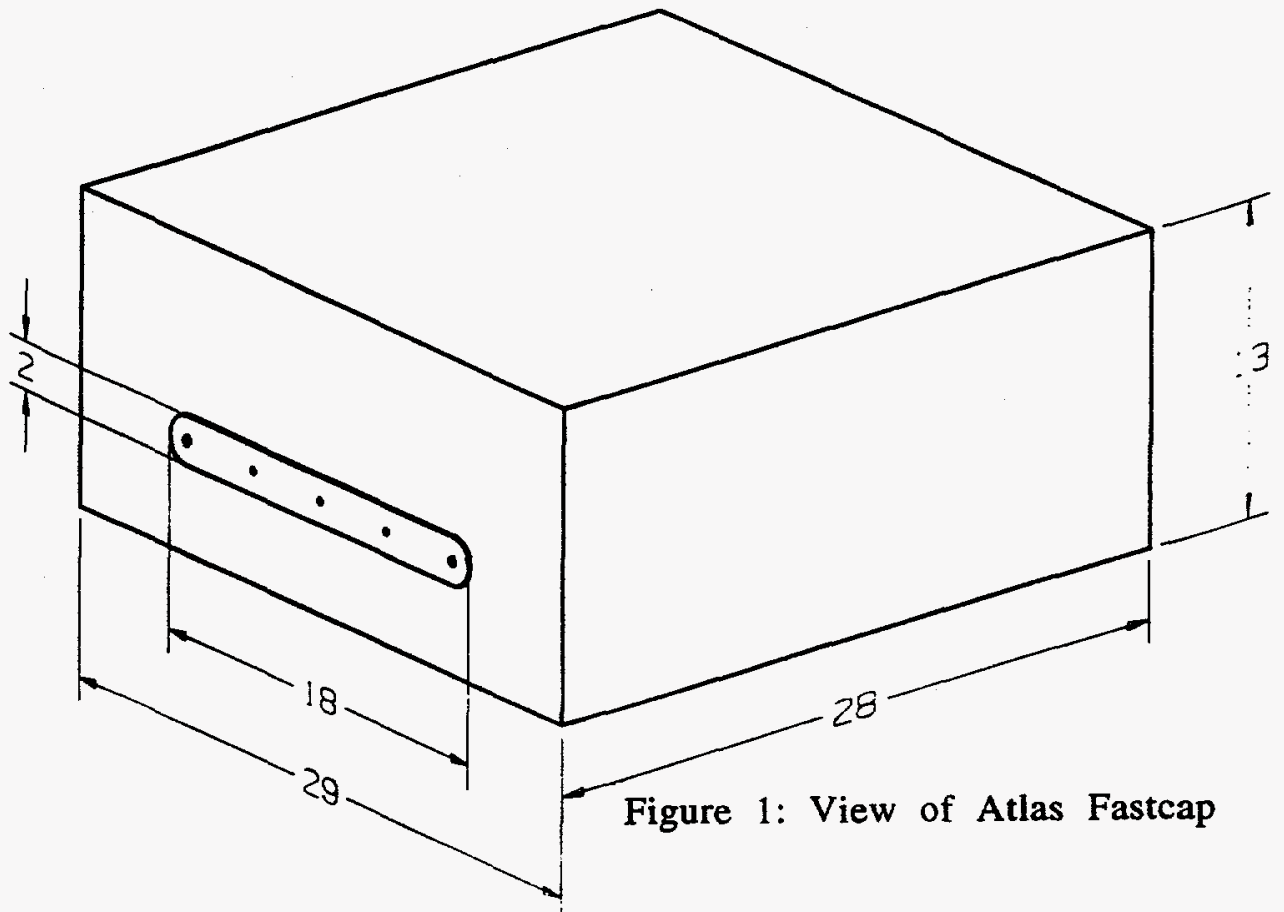

The Atlas railgaps have many design iterations to enhance their performance and reliability. Previous designs utilized a fiberglass filled cast epoxy base. The fiberglass design as shown in Figure 2, has a two piece fastener retainer to provide a high strength attachment for the covers' fasteners. Two pieces are required to permit space for the trigger rail input post (not shown), which is located between the ends of the fastener retainer. Each fastener retainer can also electrostatically charge up to a graded potential without seriously effecting the gaps' voltage compliance. The typical failure site for this gap is a fracture in the space between the retainers. This design also has two piece electrodes that are less expensive to manufacture than the Atlas design. The two piece electrode design is more prone to arcing at the current joint interfaces. Arcing can occur should any of the fastening screws become loose. Loose screws can also cause alignment problems and ash buildup, which lead to gap prefire.

The Atlas railgap design is shown in Figure 3. An obvious difference is the electrode design. One piece electrodes are utilized with an increased radius. The increased radius provides a lower divergent field in the region of the trigger electrode, hopefully reducing chances of prefire. A more robust rail fastening scheme and support structure will help maintain better electrode alignment and reduce interface arcing. The housing is made from cast polyurethane. The advantage of the cast polyurethane is its higher Izod impact strength as compared to epoxy. This provides a more resilient enclosure that is less prone to fracture, permitting higher fault 
mode currents and coulomb transfer. To prevent fracturing between the two fastener retainers, a one piece fastener retainer is used that is non-conducting. The retainer is made from G-10 with threaded inserts for the cover bolts. The trigger rail input post is moved in-board and penetrates through the cover with an o-ring seal. An acrylic liner, which protects the Lexan cover, as developed on Shiva-Star, prevents build-up of carbon based compounds that can cause prefires. The electrical arc induced byproducts from acrylic seem to be more benign than those from Lexan. With the Ar/SF6 gas mix, little oxidation occurs, switching byproducts (and metallic ash) are conductive. This necessitates frequent maintenance to minimize prefire concerns.

The Atlas gaps will use dry air, which will form non-conducting oxides with the switching by-products. This should reduce maintenance demands, prefire rates, and ES\&H concerns. Although air is more resistive than an Ar/SF6 mixture, fill pressure and reduction of electrode spacing should mitigate these effects. Air insulation produces more resistive arc channels than Ar/SF6, but the current and arc channel spacing remains more evenly distributed with closely spaced electrodes. The application of a negative polarity trigger and fast $\mathrm{dV} / \mathrm{dT}$ is important for production of good multi-channeling in the Atlas evaluations completed to date. On-going Atlas R\&D will determine what parameters are required to maximize railgap switching performance and system reliability. We will utilize a fast framing camera to better determine railgap breakdown characteristics with variations of trigger $\mathrm{dV} / \mathrm{dT}$, charge voltage, fill pressure, and gap spacing. We will continue using a 50/50 midplane trigger bias that eliminates coupling and bias networks, however, testing with the more conventional $70 / 30$ trigger bias will be performed. The midplane trigger bias permits direct connection of the trigger cable that results in a smaller trigger loop inductance and a faster $\mathrm{dV} / \mathrm{dT}$.

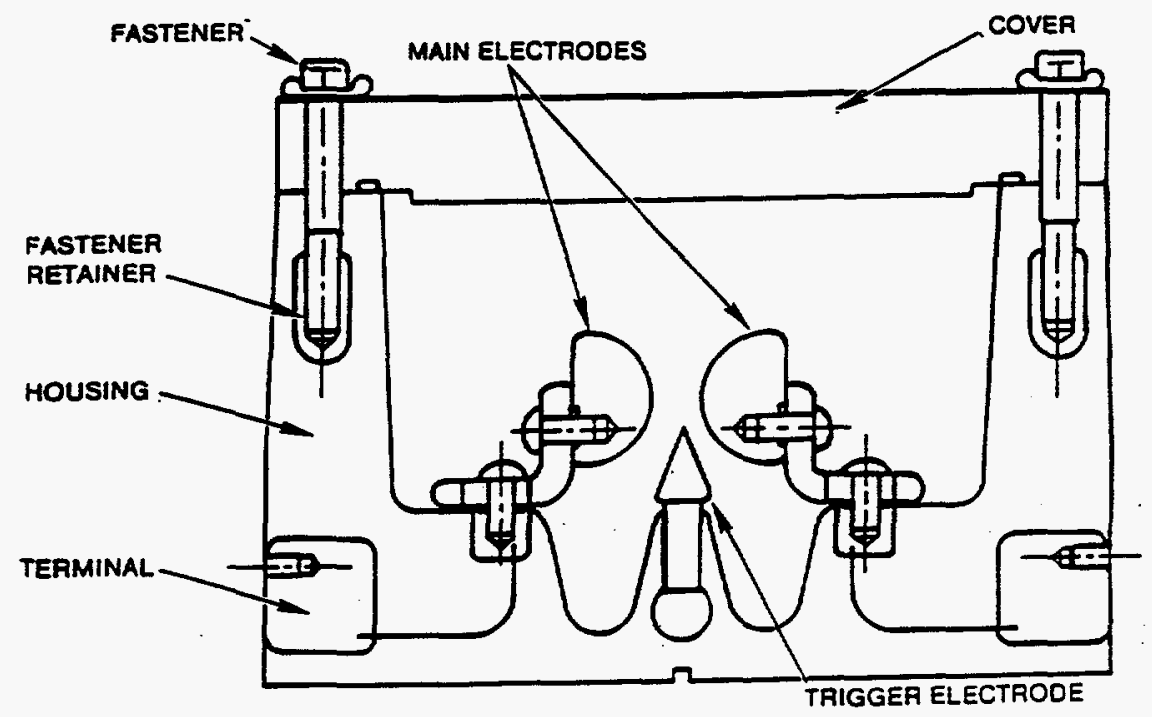

Figure 2: Original Maxwell Railgap Switch 


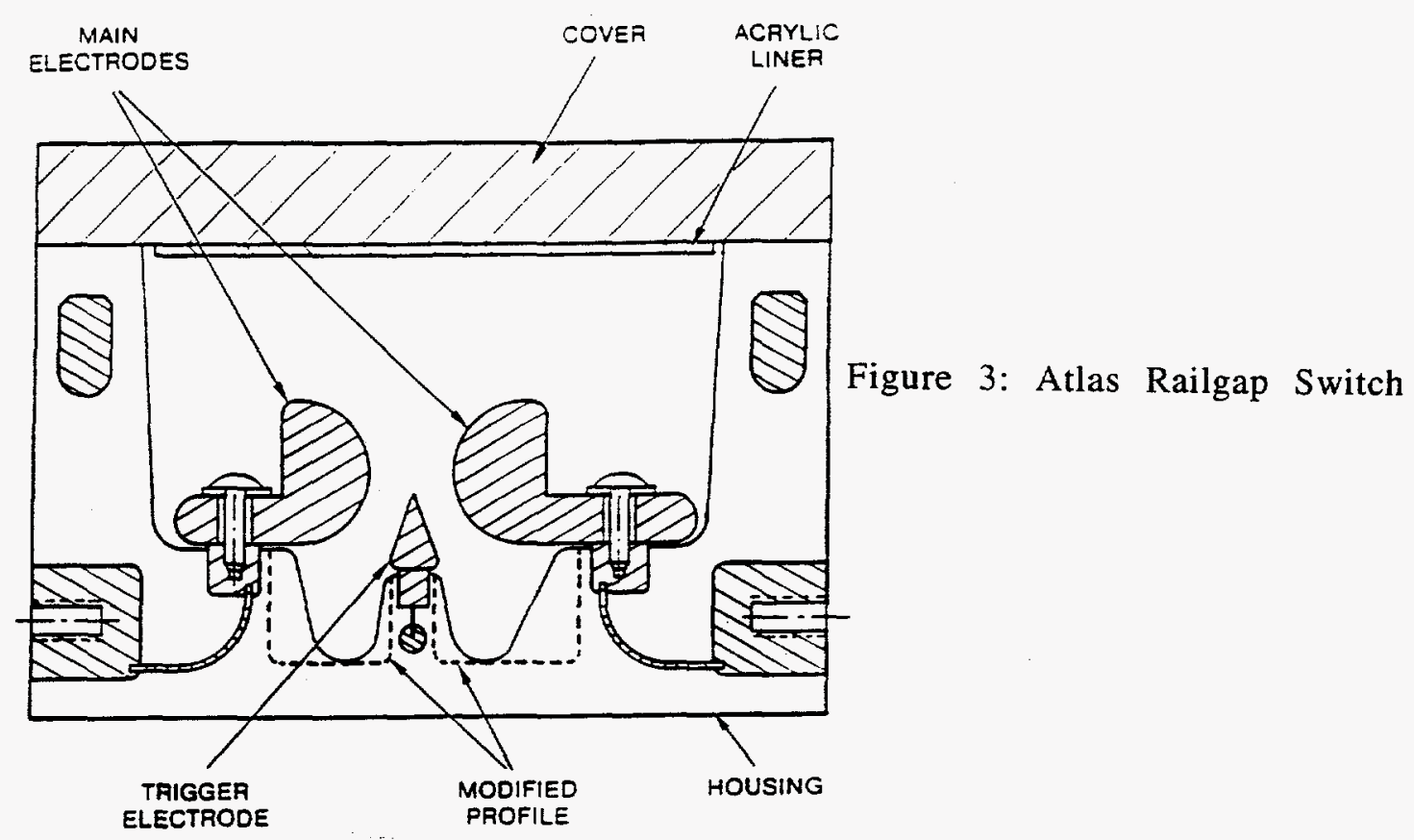

\section{RAILGAP AND CAPACITOR ASSEMBLY}

An individual Marx stage is shown in Figure 4. For this configuration, the stage inductance is about $82 \mathrm{nH}$. This assumes $15 \mathrm{nH}$ for each capacitor, $15 \mathrm{nH}$ for the space between the capacitors, and $13 \mathrm{nH}$ for the space between the opposite capacitor electrodes that connect to the output transmission line. The railgap has a published inductance of $25 \mathrm{nH}$. It is believed that actual Marx stage testing will indicate a lower inductance than $82 \mathrm{nH}$, primarily due to reduced spacing between rail electrodes and improved multi-channeling. The mechanical assembly is rather simple with the capacitor to railgap connecting rail giving adjustment for mechanical tolerances. Oversize through-holes permit tolerance build-up. The connecting rail has two contact ridges . $1^{\prime \prime}$ wide along its' length that interface to the railgap. The interface between the connecting rail and capacitor utilizes Multi-lam louvers that permit a low force joint and additional dimensional tolerance for vertically skewed (tilted) capacitor electrodes. 


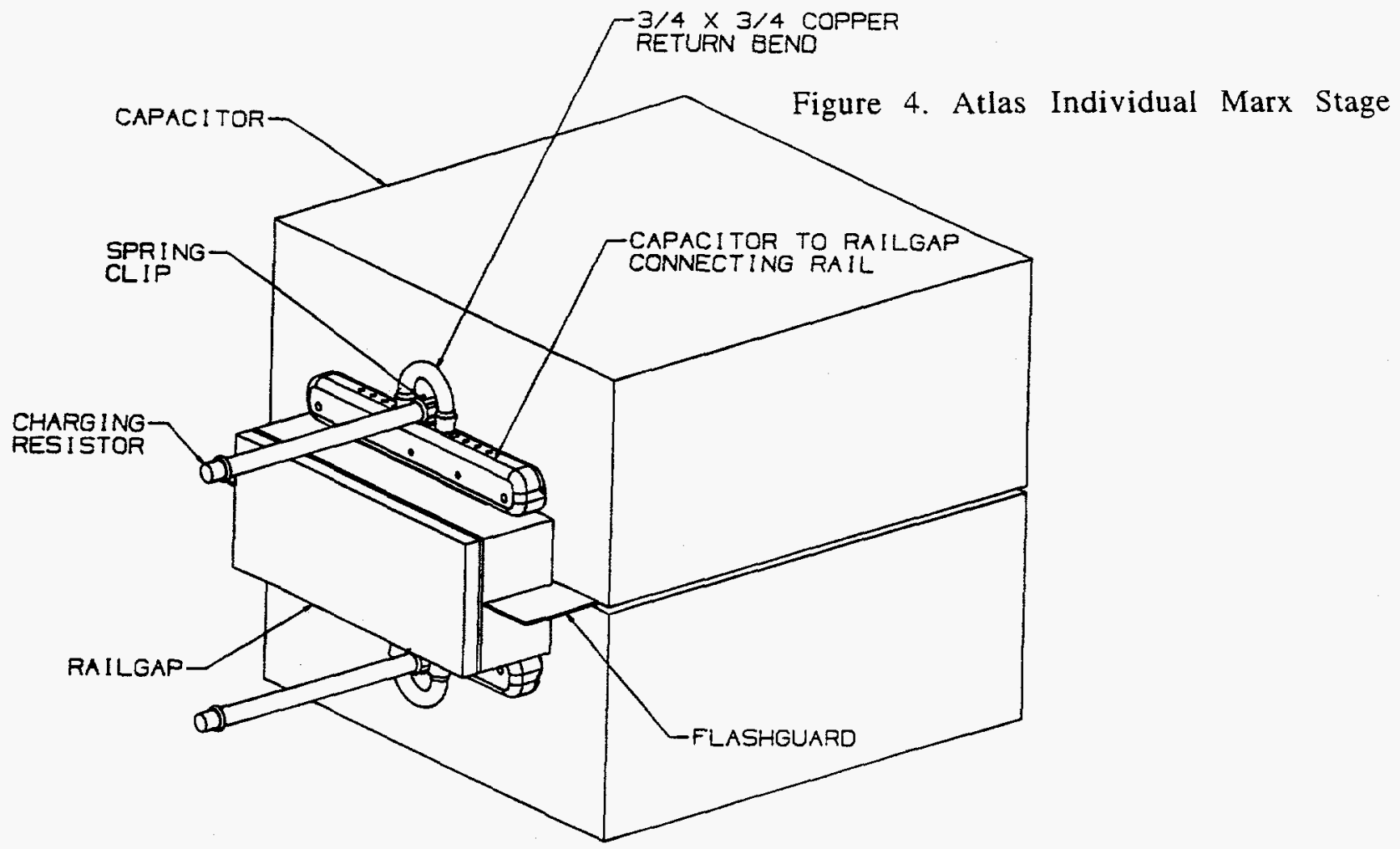

CONCLUSION

Capacitor and railgap technologies are being iterated to provide incremental performance improvements for Marx bank system design. These designs permit reduced stage inductance, reliable bank operation in air, and simplified packaging issues. High energy density capacitors minimize total system component count, and with resistive damping, minimize failures due to ringing and excessive coulomb transfer. Atlas R\&D efforts will characterize more robustly designed railgaps with $50 / 50$ trigger bias and air dielectric. This should lead to railgaps with improved electrical ratings, reduced prefire rates, and fewer maintenance requirements.

\section{ACKNOWLEDGMENTS}

The authors gratefully acknowledge the support of the Department of Energy, Defense Programs. We would particularly like to thank Dr. Vic Reis, Dr. Everett Beckner, Dr. Roger Fisher, Dr. Marshall Sluyter, Dr. Robert DeWitt, and Mr. Robert Hamby for their efforts.

\section{REFERENCES}

(1) Advanced Power Technology Program, June 85 Through October 88, DNA Contract: DNA001-85-C-0245, Maxwell Laboratories 